\title{
Severe exertional dyspnea in a patient with localized emphysema
}

\author{
Giuseppe Giustino MD FRCPC ${ }^{1}$, Katherine A Webb MSc ${ }^{1}$, Kenneth B Sutherland MD FRCPC ${ }^{2}$, \\ Denis E O'Donnell MD FRCPI FRCPC ${ }^{1}$ \\ Departments of ${ }^{1}$ Medicine and ${ }^{2}$ Radiology, Queen's University, Kingston, Ontario
}

\section{G Giustino, KA Webb. Severe exertional dyspnea in a pa- tient with localized emphysema. Can Respir J 1999;6(6):535-539.}

The case of a middle-aged, male smoker who presented with progressive severe dyspnea is described. The cause of the progressive severe dyspnea remained unexplained after a comprehensive history, physical examination, chest radiograph, electrocardiogram and spirometry. Subsequent investigations resulted in a diagnosis of localized pulmonary emphysema. Detailed exercise testing helped uncover the physiological basis of the patient's extreme dyspnea.

Key Words: Dynamic hyperinflation; Dyspnea; Exercise testing; Nonobstructive emphysema

\section{Dyspnée d'effort sévère chez un patient atteint d'emphysème localisé}

RÉSUMÉ : Le cas d'un homme dans la cinquantaine et fumeur qui manifestait une dyspnée sévère et progressive est décrit. La cause de cette dyspnée sévère et progressive est restée inexpliquée après l'anamnèse, un examen physique, une radiographie pulmonaire, un électrocardiogramme et des tests spirométriques. Des examens subséquents ont permis de poser un diagnostic d'emphysème pulmonaire localisé. Des épreuves d'effort extensives ont permis de découvrir la base physiologique de cette dyspnée extrême du patient.
$\mathrm{T}$ he case of a patient who presented with incapacitating exertional dyspnea is described. The patient had a normal chest $\mathrm{x}$-ray and minor airway obstruction on resting spirometry, but had a disproportionately low diffusion capacity for carbon monoxide. The differential diagnosis for this clinical presentation is discussed, and the value of cardiopulmonary exercise testing in uncovering the pathophysiological mechanisms of this patient's dyspnea and exercise intolerance is demonstrated.

\section{CASE PRESENTATION}

A 52-year-old male was referred to the Kingston General Hospital with a two-year history of progressive activityrelated dyspnea. He could only walk the equivalent of one block at a slow pace before stopping with dyspnea, and was forced to abandon his work as a construction worker. He derived no benefit from beta2-agonist and anticholinergic bronchodilators, or high-dose inhaled steroids. He had a 70 pack-year smoking history and was currently smoking up to two packs of cigarettes/day. He had no sputum productivity, chronic cough, hemoptysis, wheeze, atopy, or personal or family history of asthma. He had no orthopnea, paroxysmal nocturnal dyspnea, chest discomfort or ankle swelling. He had no symptoms to suggest anemia, neuromuscular disease or any systemic illness. He had worked for two years in lead and zinc mining 20 years previously, but had no respiratory symptoms at that time and had no known asbestos exposure. A full system review was otherwise unremarkable. 


\section{TABLE 1}

\section{Characteristics of patient who presented with severe dyspnea}

\begin{tabular}{|c|c|}
\hline Variable & Value \\
\hline \multicolumn{2}{|l|}{ Pulmonary function } \\
\hline Forced expiratory volume in $1 \mathrm{~s}\left(\mathrm{FEV}_{1}\right)(\mathrm{L})$ & $2.69(91)$ \\
\hline Forced vital capacity (FVC) (L) & $3.67(93)$ \\
\hline $\mathrm{FEV}_{1} / \mathrm{FVC}(\%)$ & $73(97)$ \\
\hline Maximal midexpiratory flow rate $(\mathrm{L} / \mathrm{s})$ & $1.58(50)$ \\
\hline Total lung capacity (L) & $6.22(116)$ \\
\hline Residual volume (L) & $2.32(127)$ \\
\hline $\begin{array}{l}\text { Functional residual capacity } \\
\text { (plethysmographic) (L) }\end{array}$ & $3.80(123)$ \\
\hline Functional residual capacity (dilution) (L) & $3.32(107)$ \\
\hline $\begin{array}{l}\text { Carbon monoxide diffusing capacity }\left(D_{L} C O\right) \\
(\mathrm{mL} / \mathrm{min} / \mathrm{mmHg})\end{array}$ & $8.7(43)$ \\
\hline $\begin{array}{l}\mathrm{D}_{\mathrm{L}} \mathrm{CO} / \mathrm{Alveolar} \text { ventilation }\left(\mathrm{V}_{\mathrm{A}}\right) \\
(\mathrm{min} / \mathrm{mmHg})\end{array}$ & $1.69(41)$ \\
\hline Maximal inspiratory pressure $\left(\mathrm{cm} \mathrm{H}_{2} \mathrm{O}\right)$ & $60(53)$ \\
\hline$\Delta \mathrm{FEV}_{1}$ with beta 2 -agonist, $\mathrm{L}(\%)$ & $0.12(+4 \%)$ \\
\hline \multicolumn{2}{|l|}{ Peak exercise } \\
\hline Oxygen consumption (L/min) & $0.60(34)$ \\
\hline Work rate $(\mathrm{W})$ & $40(28)$ \\
\hline Heart rate (beats/min) & $108(61)$ \\
\hline Oxygen saturation (\%) & 100 \\
\hline Ventilation (L/min) & $39.5(74)$ \\
\hline Frequency (breaths/min) & 42 \\
\hline Tidal volume $\left(\mathrm{V}_{\mathrm{T}}\right)(\mathrm{L})$ & 0.95 \\
\hline Inspiratory capacity (\% predicted) (L) & $1.65(73)$ \\
\hline Pes/PImax (\%) & 30 \\
\hline Pes/PImax : $V_{T} /$ predicted VC & 0.80 \\
\hline
\end{tabular}

Values in parenthesis are percentage predicted for pulmonary function and percentage predicted maximum for exercise. Predicted values for spirometry, lung volumes, diffusing capacity and maximal inspiratory pressures are from Morris (7), Goldman and Becklake (8), Burrows et al (9), and Black and Hyatt (10), respectively. Predicted values for maximum exercise are from Jones (11): maximum work rate for males $(W)=[2169 \times$ height $(\mathrm{m})-9.63 \times$ age $+4.00 \times$ weight $(\mathrm{kg})-2413 \mathrm{j} / 6.1$; maximum oxygen consumption for males $(L / \mathrm{min})=3.45 \times$ height $(\mathrm{m})-0.028 \times$ age $+0.022 \times$ weight $(\mathrm{kg})-3.76$. Pes Esophageal pressure; PImax Maximum inspiratory pressure

On physical examination, this man was of normal body weight (height $163 \mathrm{~cm}$; weight $68 \mathrm{~kg}$; body mass index $25.6 \mathrm{~kg} / \mathrm{m}^{2}$ ), with no evidence of peripheral muscle wasting. It was evident that even the minor activity of undressing and moving to the examination table evoked apparent respiratory distress. Respiratory rate was 16 breaths/min, resting oxygen saturation was $95 \%$ on room air; there was no cyanosis or clubbing, and no signs of lung hyperinflation. Breath sounds were not reduced in intensity. There were no signs of cardiovascular disease, including pulmonary hypertension. Abdominal and neurological examinations were normal.

Investigations: A chest $\mathrm{x}$-ray was reported as normal with minor bilateral pleural thickening only. Spirometry showed forced expiratory time of $1 \mathrm{~s}\left(\mathrm{FEV}_{1}\right)$ of $90 \%$ predicted, and a $\mathrm{FEV}_{1} /$ forced vital capacity (FVC) ratio of $73 \%$ predicted. Pulmonary function test results are reported in Table 1, and revealed a severely reduced diffusion capacity and trapped gas $(0.48 \mathrm{~L}$ is the difference between measurements of functional residual capacity (FRC) obtained by body ple-

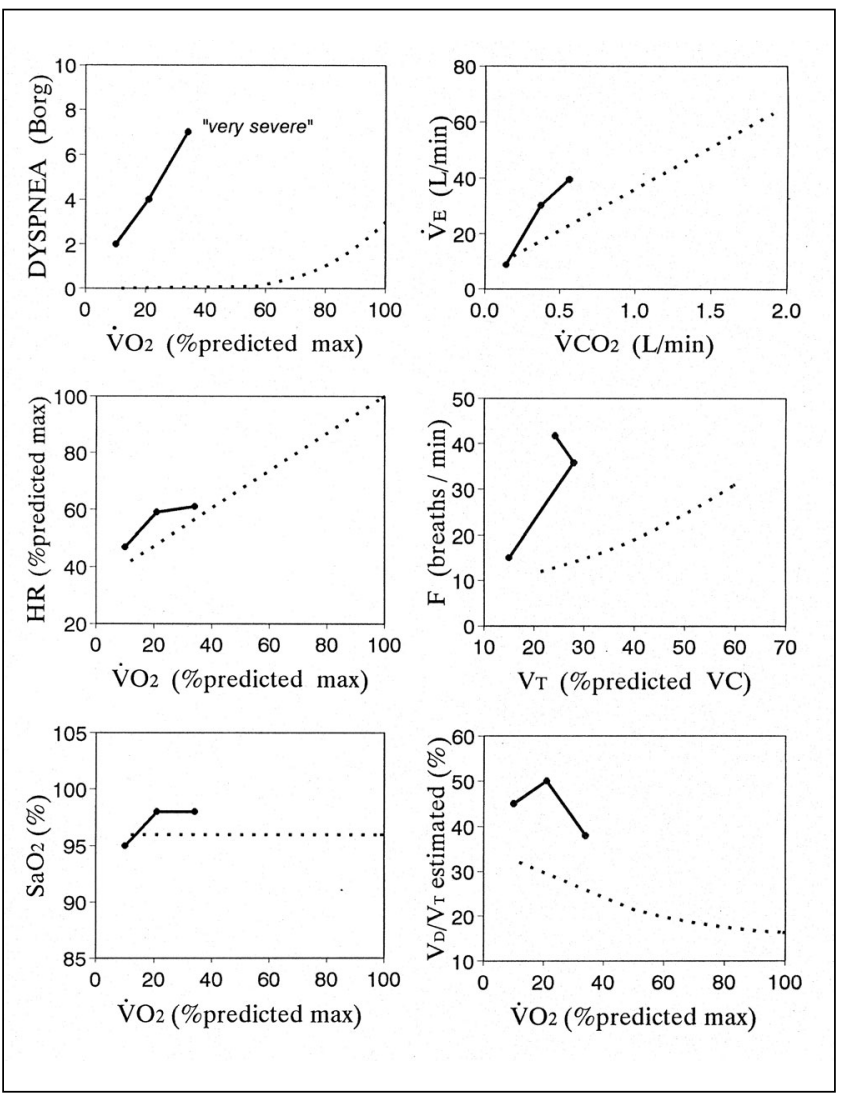

Figure 1) Exercise responses are shown for the patient (solid lines) in comparison with normal predicted responses (dotted lines). See text for interpretation. F Breathing frequency; $\mathrm{HR}$ Heart rate; $\mathrm{SaO}_{2}$ Oxygen saturation; $V_{T}$ Tidal volume (standardized as percentage of predicted vital capacity [VC]); $\dot{V} \mathrm{CO}_{2}$ Carbon dioxide production; $V_{D} / V_{T}$ Dead space gas volume to tidal volume (physiological dead space); $V_{E}$ Ventilation; $\dot{V} \mathrm{O}_{2}$ Oxygen consumption (standardized as percentage of predicted maximum)

thysmography and by dilution). There was no significant improvement in response to bronchodilators: $\mathrm{FEV}_{1}$ improved by only $4 \%$ or $0.12 \mathrm{~L}$ after $200 \mu \mathrm{g}$ salbutamol. Steady-state arterial blood gases at rest on room air showed a partial pressure of arterial oxygen of $73.5 \mathrm{mmHg}$, partial pressure of arterial carbon dioxide $34.9 \mathrm{mmHg}$, mixed expired carbon dioxide $13.8 \mathrm{mmHg}, \mathrm{pH} 7.42$, bicarbonate $20.2 \mathrm{mmol} / \mathrm{L}$, and a physiological dead space (dead space gas volume $\left[\mathrm{V}_{\mathrm{D}}\right]$ to tidal volume $\left[\mathrm{V}_{\mathrm{T}}\right]$ ) of $45 \%$, while breathing with a $\mathrm{V}_{\mathrm{T}}$ of 0.59 $\mathrm{L}$ and a respiratory rate of 15 breaths/min. Complete blood count, urea, creatinine and electrolytes were normal. Electrocardiogram was normal.

To evaluate this patient's dyspnea and to gain mechanistic insights into its cause, an incremental exercise test was conducted (Table 1, Figure 1). The patient stopped exercise because of 'very severe' dyspnea (ie, a peak Borg rating of 7) at a work rate of only $28 \%$ of the predicted maximum, and an oxygen consumption $\left(\mathrm{VO}_{2}\right)$ of $10 \mathrm{~mL} / \mathrm{kg} / \mathrm{min}$. The slope of ventilation over carbon dioxide output was elevated compared with normal, and the patient had a rapid shallow breathing pattern; $\mathrm{PaCO}_{2}$ of $22.7 \mathrm{mmHg}$ and end-tidal carbon dioxide $\left(P_{\mathrm{ETCO}}\right)$ of $14.5 \mathrm{mmHg}$ were diminished, indi- 


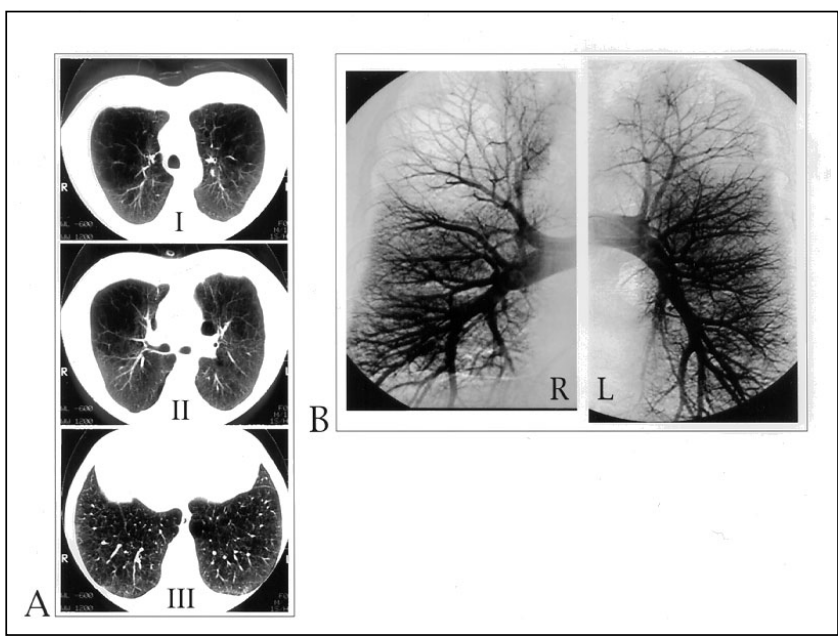

Figure 2) A High resolution computed tomography images $(2 \mathrm{~mm}$ thick) obtained at levels of the inferior transverse aortic arch (I), the carina (II) and the right diaphragmatic dome (III) demonstrate the asymmetric loss of lung parenchyma in a pattern and distribution consistent with centrilobular emphysema. The anterior and apical regions of the upper lobes have the most severe changes with minimal involvement in the remaining lung. B Pulmonary angiogram. Selected images obtained from each main pulmonary artery trunk injection during the early capillary phase of the study are shown. Each demonstrates both the absence of significant pulmonary vascular disease, and the localized disruption of the capillary beds in the upper lobes due to the emphysema

cating alveolar hyperventilation. $\mathrm{V}_{\mathrm{D}} / \mathrm{V}_{\mathrm{T}}$ was elevated at rest and failed to decline as normal during exercise. There was no arterial oxygen desaturation during exercise, and heart rate responses were within normal limits.

Several investigations were undertaken to determine whether pulmonary vascular disease was present. A ventilation-perfusion $(\mathrm{V} / \mathrm{Q})$ scan was interpreted as showing a low probability for pulmonary embolism, and demonstrated only matched $\dot{\mathrm{V}} / \mathrm{Q}$ defects in both upper lobes without an appreciable difference in size between the ventilation or perfusion portions. However, a precise quantification of $\dot{\mathrm{V}} / \dot{\mathrm{Q}}$ mismatching was not possible. A high resolution computed tomography (HRCT) scan of the thorax showed asymmetric emphysema in a pattern consistent with centrilobular type. The emphysematous changes were more localized, and severe in the anterior and apical aspects of both upper lobes, the right more so than the left (Figure 2A). There was no evidence of increased interstitial markings to indicate fibrosis; minor bilateral pleural thickening was present. A pulmonary angiogram was undertaken to rule out co-existing pulmonary vascular diseases because of the concern that his severe dyspnea was disproportionate to the severity of emphysema. The angiogram showed bilateral areas of pulmonary vascular attenuation confirming the extent and asymmetry of the emphysema (Figure 2B). There was no evidence of acute or chronic thromboembolic disease, or other pulmonary vascular disorders. Mean pulmonary artery pressure was $30 \mathrm{mmHg}$. Antinuclear factor, rheumatoid factor and alpha1-antitrypsin levels were all in the normal range.

To study further the possible mechanisms of this patient's

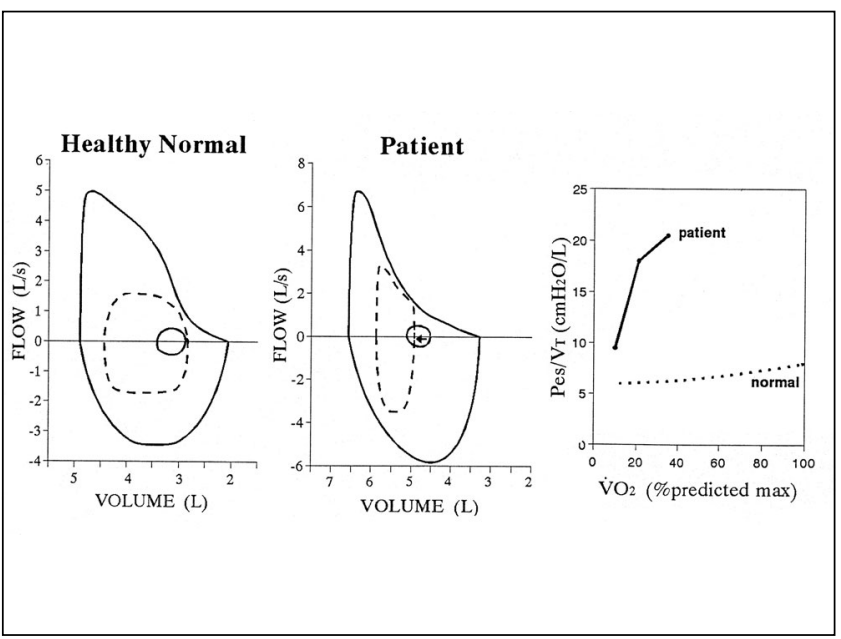

Figure 3) Maximal flow-volume loops are shown for a normal subject (left panel) and the present patient (middle panel) with tidal loops at rest (solid lines) and at peak exercise (dashed lines). Note dynamic hyperinflation and expiratory flow limitation during exercise in our patient. In the patient at his very low peak oxygen consumption $\left(\dot{V}_{2}\right)$, inspiratory reserve volume is comparable with that of normal individuals at a much higher peak $\dot{V} O_{2}$. Esophageal pressure $(P e s)$ to tidal volume $\left(V_{\mathrm{T}}\right)$ ratios during exercise (right panel) increase progressively in the patient, in contrast with remaining relatively constant in healthy normals $(n=12)$. Normal values from reference 1

dyspnea, esophageal pressure (Pes) and repeated inspiratory capacity (IC) measurements during exercise were evaluated; the latter measurement was also used to plot tidal flowvolume loops during exercise relative to the maximal resting flow-volume loop (Figure 3). The ventilatory constraints in the patient at the breakpoint of symptom-limited exercise (Table 1) were significantly greater than those of a previously studied age-matched healthy group at a comparable metabolic load (1). Due to the high ventilatory demand of exercise in this patient, he became flow-limited early in the exercise, with a consequent increase in end-expiratory lung volume of $0.45 \mathrm{~L}$ at peak exercise. This resulted in significant mechanical restriction indicated by a marked reduction in inspiratory reserve volume (IRV) $(0.70 \mathrm{~L})$, an increased $\mathrm{V}_{\mathrm{T}} / \mathrm{IC}$ ratio $(58 \%)$, and an end-inspiratory lung volume reaching $90 \%$ of total lung capacity (TLC) at this low peak $\mathrm{VO}_{2}$, in striking contrast with the healthy group at a comparable $\mathrm{VO}_{2}$, where IRV, $\mathrm{V}_{\mathrm{T}} / \mathrm{IC}$, and end-inspiratory lung volume to TLC ratio were $1.91 \mathrm{~L}, 38 \%$ and $71 \%$, respectively. The magnitude of respiratory effort (the tidal Pes swing relative to the maximal inspiratory pressure [Pes/PImax]) and its relationship to the resultant thoracic displacement $\left(\mathrm{V}_{\mathrm{T}}\right.$ standardized as a fraction of the predicted vital capacity $\left[\mathrm{V}_{\mathrm{T}} /\right.$ predicted VC]) were also elevated relative to normal (Figure 3). Finally, functional muscle strength (static and dynamic PImax) did not change from rest to peak exercise in this patient.

\section{DISCUSSION}

The cause of this patient's severe dyspnea was unexplained after a thorough history, physical examination, spiro- 
metry, chest x-ray and baseline laboratory studies. The combined findings of a low diffusion capacity, trapped gas, high resting and exercise physiological deadspace, and a high ventilatory equivalent for carbon dioxide in this patient suggested a diagnosis of emphysema. Other diagnostic considerations included pulmonary vascular disease other than emphysema, interstitial lung disease and mixed obstructive interstitial disease. An HRCT scan showed evidence of localized upper lobe centrilobular emphysema. The absence of increased interstitial markings on the HRCT and the absence of arterial oxygen desaturation during exercise made the diagnosis of interstitial lung disease or mixed obstructiveinterstitial disease less likely. Localized bi-apical airspace disruption on HRCT is a common, well recognized radiographic presentation of centrilobular emphysema in smokers $(2,3)$. However, atypical features of this presentation, such as the relatively young age of onset, rapid progression to disabling dyspnea, and demonstration of only minor reduction in FEV1, despite apparent localized disease on CT scan, gave rise to concerns about co-existent pulmonary vascular disease. Pulmonary angiography, however, confirmed that localized, bilateral upper lobe attenuation corresponded well with the areas of emphysematous change on HRCT scan. Notably, there were no angiographic features of acute or chronic thromboembolic disease, primary pulmonary hypertension or vasculitis.

Recently, the term 'nonobstructive' emphysema has been coined to describe patients such as ours, who present with dyspnea but have a normal chest $\mathrm{x}$-ray and spirometry (FEV1, FVC), and an 'isolated' low diffusion capacity. Klein et al (4), in reviewing 470 HRCT studies, identified 10 symptomatic subjects with localized emphysema who had the above outlined clinical features. In this group of patients $(\mathrm{n}=10)$, the single breath diffusion capacity $(55 \pm 14 \%$ predicted, mean $\pm \mathrm{SD}$ ), but not the FEV1 correlated well with HRCT emphysema scores ( $\mathrm{r}=-0.643)$. De Paso et al (5), in reviewing 75 patients with dyspnea unexplained by history, examination, spirometry or chest radiograph, found that two of these had an isolated low diffusion capacity (less than $40 \%$ predicted) and bullous 'nonobstructive' emphysema. Chin et al (6), recently described a patient with exertional dyspnea, normal spirometry and a low diffusion capacity (57\% predicted), who was found to have heterogeneous emphysema on HRCT scan. Exercise testing was not performed in any of the previous studies, nor were the mechanisms of dyspnea explored.

The results of the investigations in our patient confirm that nonobstructive emphysema is a misnomer. We suspect that many such patients previously given this diagnostic label may in fact have localized emphysema with extensive dynamic small airway dysfunction, such as our patient did. Current criteria for disease severity based exclusively on the FEV1 are imprecise and are only loosely linked to symptom severity and disability. Moreover, because mechanisms of dyspnea can vary greatly among patients with emphysema, patients should be investigated on an individual basis.

Evidence for dynamic small airway dysfunction during exercise is derived from the demonstration of expiratory flow limitation and dynamic lung hyperinflation. At the symptomatic breakpoint of exercise, the patient mustered relatively large efforts, in the face of an increasingly restricted mechanical response. In contrast with the healthy state, where the ratio between inspiratory effort and the resultant volume response remains fairly constant throughout exercise, this ratio was increased in our patient due to increased elastic loading due to hyperinflation and the resultant 'high end' pressure-volume mechanics; decreased dynamic compliance, which was probably frequency dependent (dynamic compliance decreased from 140 to $61 \mathrm{~mL} / \mathrm{cm} \mathrm{H2O}$ ); increased resistive loading, particularly at high levels of ventilation; reduced functional muscle strength (PImax) due to increased velocity of shortening and length-tension abnormalities; and increased volume restriction due to dynamic hyperinflation (ie, the decreased IC results in an increased VT/IC ratio). We have recently shown that this effortdisplacement ratio (Pes/PImax to VT/predicted VC) correlates strongly with the intensity of inspiratory difficulty during exercise in chronic obstructive pulmonary disease (1).

Although this patient had no symptoms of morbid anxiety or hyperventilation syndrome per se, relatively low levels of $\mathrm{PaCO} 2$ and PETCO2 during exercise revealed acute alveolar hyperventilation. This accelerated ventilatory response undoubtedly contributed to the patient's dynamic mechanical abnormalities during exercise, and to the intensity and quality of his dyspnea. Anxiety hyperventilation may have provoked dyspnea a priori or may represent the affective response to extreme respiratory discomfort during exercise. Chronic alveolar hyperventilation is well described in dyspneic emphysematous patients. It is noteworthy that this patient's ventilatory response to exercise was consistently elevated despite repeated exercise testing, indicating that unfamiliarity with laboratory exercise testing was not the explanation.

This patient was restarted on high dose bronchodilator therapy to no avail. He underwent an eight-week multimodality exercise endurance training program, but surprisingly benefited only minimally from this. A trial of oxygen therapy and anxiolytics was also unhelpful. Meanwhile, because of his continued cigarette smoking, he now shows evidence of worsening airflow obstruction (two years after his initial presentation, FEV1 has decreased to $77 \%$ predicted, and FRC has increased to $142 \%$ predicted). Because of his level of disability and handicap, he is being considered for a surgical option such as lung volume reduction surgery, or lung transplantation as a last resort.

\section{CONCLUSIONS}

This symptomatic patient exhibited many of the clinical features of what has erroneously been termed 'nonobstructive emphysema' in the past. This case demonstrated that the presence of localized pulmonary emphysema and relatively preserved resting spirometry does not preclude the existence of marked abnormalities of dynamic ventilatory mechanics, with attendant dyspnea when challenged by the stress of exercise. 


\section{REFERENCES}

1. O'Donnell DE, Bertley JC, Chau LK, Webb KA. Qualitative aspects of exertional breathlessness in chronic airflow limitation: pathophysiologic mechanisms. Am J Respir Crit Care Med 1997;155:109-15.

2. Gurney JW, Jones KK, Robbins RA, et al. Regional distribution of emphysema: correlation of high-resolution CT with pulmonary function tests in unselected smokers. Radiology 1992;183:457-63.

3. Martelli NA, Hutchison DC, Barter CE. Radiological distribution of pulmonary emphysema. Clinical and physiological features of patients with emphysema of upper or lower zones of lungs. Thorax 1974;29:81-9.

4. Klein JS, Gamsu G, Webb WR, Golden JA, Muller NL. High-resolution CT diagnosis of emphysema in symptomatic patients with normal chest radiographs and isolated low diffusing capacity. Radiology 1992;182:817-21.

5. De Paso WJ, Winterbauer RH, Lusk JA, Dreis DF, Springmeyer SC. Chronic dyspnea unexplained by history, physical examination, chest roentgenogram, and spirometry. Analysis of a seven-year experience. Chest 1991;100:1293-9.

6. Chin NK, Lim TK. A 39-year old smoker with effort dyspnea, normal spirometry results, and low diffusing capacity. Chest 1998;113:231-3.

7. Morris JF. Spirometry in the evaluation of pulmonary function. West $\mathbf{J}$ Med 1976;125:110-1.

8. Goldman HI, Becklake MR. Respiratory function tests - normal values at median altitudes and the prediction of normal results. Am Rev Tuberc 1959;79:457-67.

9. Burrows B, Kasik JE, Niden AH, Barclay WR. Clinical usefulness of the single-breath pulmonary diffusing capacity test. Am Rev Respir Dis 1961;84:789-806.

10. Black LF, Hyatt RE. Maximal respiratory pressures: normal values and relationship to age and sex. Am Rev Respir Dis 1969;99:696-702.

11. Jones NL. Clinical Exercise Testing, 3rd edn. Toronto: WB Saunders Company, 1988:306-7. 


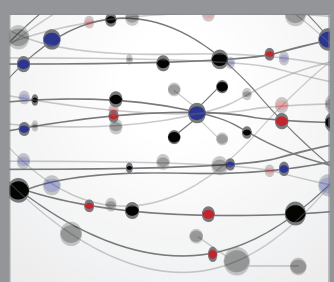

The Scientific World Journal
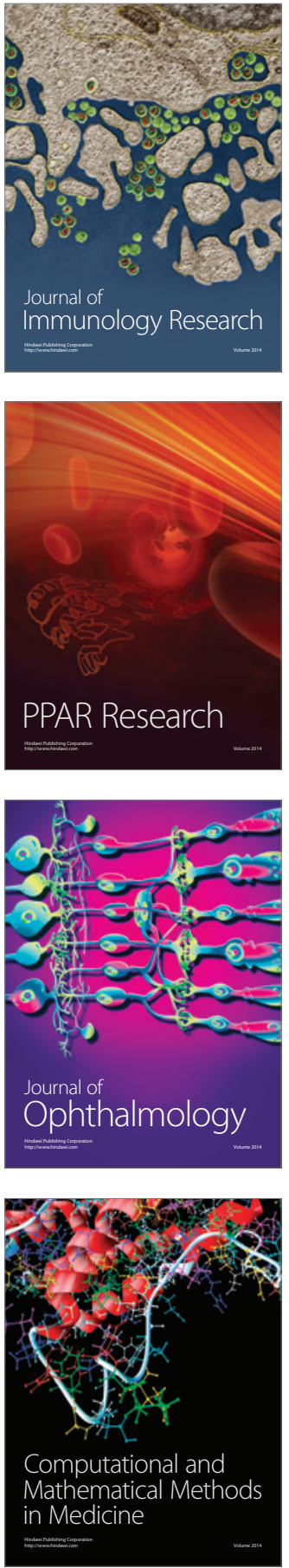

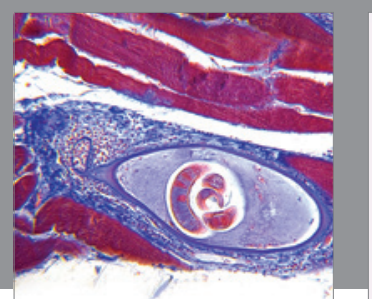

Gastroenterology Research and Practice

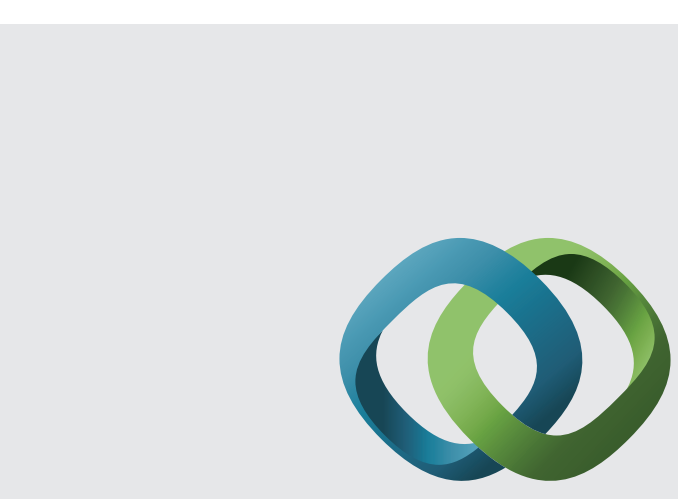

\section{Hindawi}

Submit your manuscripts at

http://www.hindawi.com
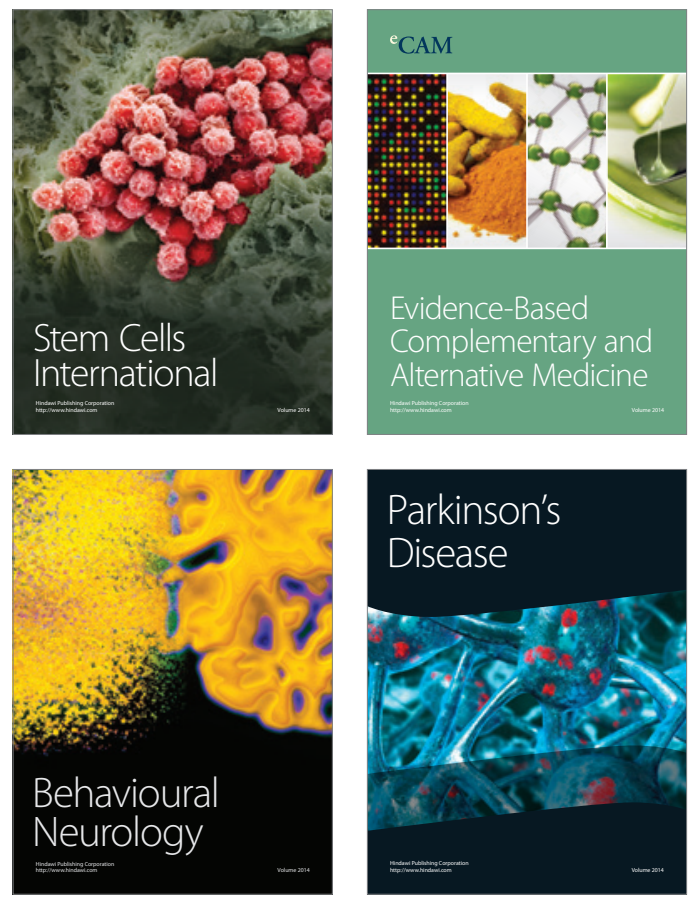
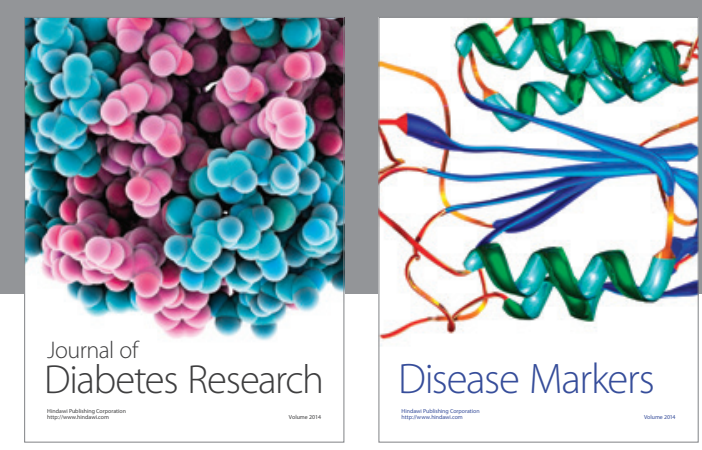

Disease Markers
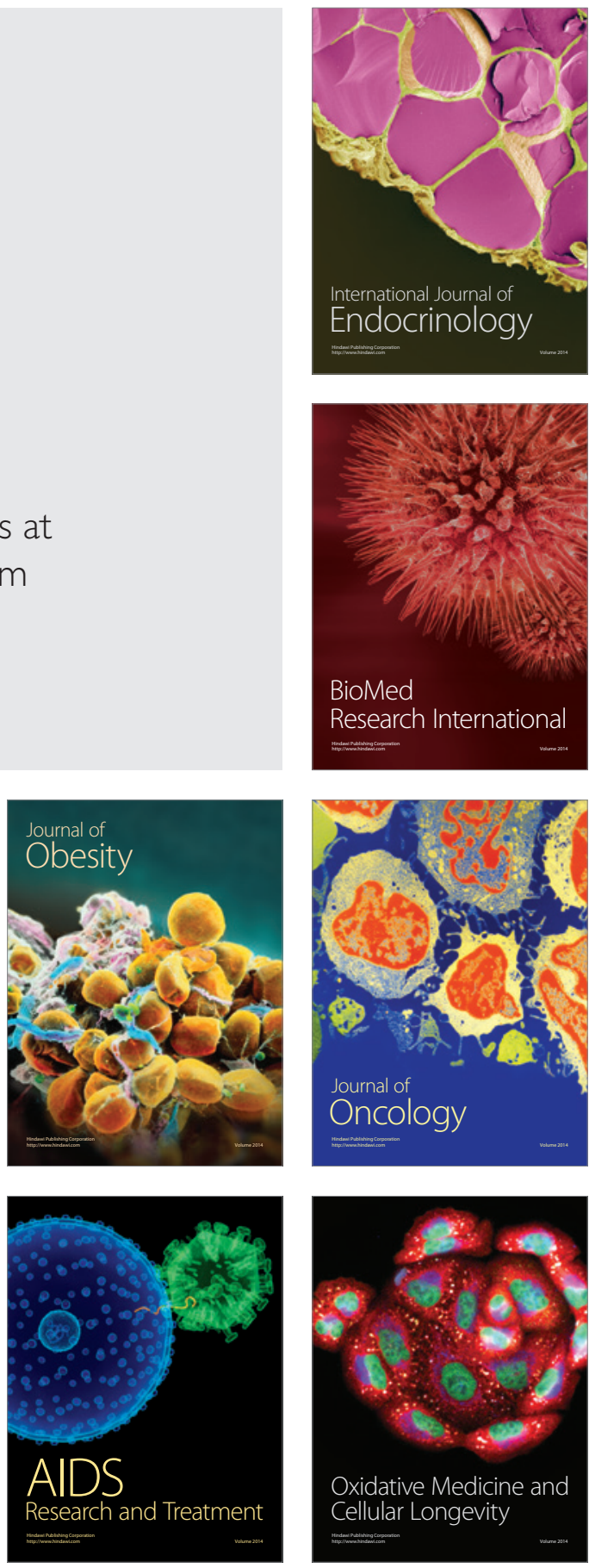